\title{
Características clinicoepidemiológicas de um grupo de mulheres com HIV/AIDS em Salvador-Bahia
}

\author{
Clinical-epidemiological characteristics of a group of HIV/AIDS \\ infected women in Salvador-Bahia
}

\author{
Ceuci de Lima Xavier Nunes ${ }^{1}$, Lívia A. Gonçalves², \\ Patrícia T. Silva ${ }^{1}$ e José Carlos Bina ${ }^{3}$
}

\begin{abstract}
RESUM0
A expansão da infecção pelo HIV/AIDS entre as mulheres e os mais pobres, são importantes características da epidemia no Brasil e no mundo. Estudo descritivo delineou-se com objetivo de descrever um grupo de 82 mulheres com HIV/AIDS de Salvador - Bahia. Aidade média é $32 \pm 7,2$ anos; 75\% têm filhos, 82,5\% estão desempregadas e o grau de instrução situa-se entre analfabeto e primeiro grau em $77,8 \%$. O número de parceiros sexuais foi igual ou inferior a cinco na vida em $71 \%$ dos casos e $25 \%$ relatavam um único parceiro. Quarenta e seis (55,4\%) mulheres apresentaram 77 episódios de infecções oportunistas. A maioria das pacientes tem baixo grau de instrução, baixa renda e poucos parceiros sexuais. Aforma de transmissão foi predominantemente sexual, muitas mulheres adquiriram o vírus com o próprio companheiro/ marido.
\end{abstract}

Palavras-chaves: AIDS. HIV. Mulheres. Feminização. Pobreza.

\begin{abstract}
The increasing number of HIV/AIDS infected women is one of the main characteristics of the AIDS epidemic, besides the wide expansion of the disease among the poor. This study focused on a group of 82 women with AIDS from Salvador Bahia. The mean age was $32 \pm 7.2$ years, $75 \%$ had children, $82.5 \%$ were jobless, and $77.8 \%$ were illiterate or only had basic education. The number of sexual partners was five or fewer in $71 \%$ of cases and $25 \%$ had only one sexual partner. Forty-six (55.4\%) women reported up to 77 episodes of opportunist infections. The majority of the patients were from the lower classes, with no good education, a low income and few sexual partners. The main via of transmission was heterosexual, and many of the women were infected by their steady partner/husband.
\end{abstract}

Key-words: AIDS. HIV. Women. Feminization. Poverty.

A expansão da síndrome da imunodeficiência humana (AIDS) entre as mulheres vem sendo observada em quase todo 0 mundo 81222242833 , e estas representam 50\% dos casos no mundo e $30 \%$ dos casos da América Latina ${ }^{32}$. № Brasil, esta constatação foi feita pelo Ministério da Saúde, ao serem analisadas as notificações do período de 1994 a 1998, onde 0 crescimento entre os homens foi de $10,2 \%$ e entre as mulheres de $75,3 \%$. Observou-se também que 0 crescimento da transmissão heterossexual foi de 113\%, contra 8,6\% entre homo/ bissexual ${ }^{1718}$. De 1980 a 2002, foram notificados 257.780 casos de AIDS, sendo 72.719 mulheres, representando $28,2 \%$ dos casos totais e $36,5 \%$ dos casos novos ${ }^{19}$.

$\mathrm{Na}$ Bahia, os primeiros casos em mulheres foram notificados em 1987. Até 2002, 1470 casos foram notificados, destes, 981 são tidos como vivos. Nestes casos, a forma de transmissão foi sexual em 871 casos, representando 59,3\% do total, 182 (12,4\%) eram usuárias de drogas injetáveis (UDI) e 99 (6,7\%) adquiriram a infecção por transfusão de sangue ${ }^{21}$.

Além da feminização, outro aspecto importante da epidemia é a pauperização da AIDS, com seu alastramento

\footnotetext{
1. Escola Baiana de Medicina e Saúde Pública, Salvador, BA. 2. Hospital Português, Salvador, BA. 3. Hospital São Rafael da Universidade Federal da Bahia, Salvador, BA.

Endereço para correspondência: Dra. Ceuci de Lima Xavier Nunes. R. Martins de Almeida 60, Jardim Apipema, 40155-060 Salvador, BA.

Tel: 71 245-3808, Fax: 71 245-0952

e-mail: ceuci@uol.com.br

Recebido em 8/9/2003

Aceito em 20/8/2004
} 
para as camadas de menor poder aquisitivo da população ${ }^{25}$. No Brasil, este dado foi avaliado de forma indireta, através do nível de escolaridade, a partir das fichas de notificação, que caiu de forma progressiva de 1985 a 1988/198926. Alguns autores apontam para o especial empobrecimento das mulheres, decorrentes de preconceito de raça, etnia e, sobretudo, de gênero ${ }^{11025}$

Dados do Instituto Brasileiro de Geografia e Estatística (IBGE) mostram que a mulher brasileira além de ser a chefe de domicílio em $24,9 \%$ das famílias brasileiras e $25,9 \%$ das famílias nordestinas, têm baixa renda (média de $\mathrm{R} \$ 164,20$ no nordeste) e baixa escolaridade, sendo $21,2 \%$ analfabetas ${ }^{14}$. 0 imbricamento destes dois dados, pauperização e feminização da AIDS aponta para um grave problema social, com cada vez mais famílias sem condições mínimas de sobrevivência ${ }^{2}$. No Brasil, estima-se 0 número de órfãos da AIDS de 1987 a 1999 em 30.000, só no ano de 1999, 5.500 menores de 15 anos ficaram órfãos em decorrência da AIDS ${ }^{30}$.

Fatores anatômicos e biológicos fazem com que a transmissão do vírus seja mais efetiva do homem para a mulher, sendo que a maior quantidade do vírus no sêmen e a maior quantidade de sêmen quando comparado com a secreção vaginal são os fatores mais importantes ${ }^{1631}$. Afalta de controle da mulher sobre as práticas de sexo seguro é também considerado importante, para justificar esta tendência da epidemia ${ }^{1013}$.

Entre os fatores biológicos que facilitam a infecção pelo HIV, destacam-se as doenças sexualmente transmissíveis (DST), tanto as ulcerativas, como as não ulcerativas, cuja presença eleva de duas a quatro vezes 0 risco de infecção pelo HIV ${ }^{9} 15232$.

Os principais preditores de risco de progressão da doença e sobrevida nos pacientes infectados pelo HIV, são o número de linfócitos T CD4 $4^{+}$e 0 nível de RNA viral (Carga viral). Embora existam estudos com resultados conflitantes, a literatura médica tem mostrado diferenças na dinâmica viral entre 0 homem e a mulher que se manifestam com a diferença do nível de Carga Viral para um número semelhante de linfócitos T CD4+. Como a progressão para AIDS e morte é semelhante no homem e na mulher, provavelmente a mulher desenvolve doença com um nível da carga viral menor, indicando ser o nível de T CD4+ um melhor indicador para basear a indicação de tratamento do que a carga viral ${ }^{62} 29$.

\section{MATERIAL E MÉTODOS}

No presente estudo foram estudadas 82 mulheres matriculadas no Serviço de Ambulatório Especializado (SAE) do Hospital Couto Maia, atendidas em dia e horário exclusivos, no período de junho de 1998 a janeiro de 2002. 0 atendimento foi prestado pela autora diretamente, ou por intermédio da supervisão a médicos residentes de doenças infecciosas e parasitárias.

0 projeto foi aprovado pela Diretoria Técnica da Instituição. A cada mulher foi apresentado um Termo de
Consentimento Livre e Esclarecido, contendo os objetivos da pesquisa e a garantia da privacidade. Após a assinatura, todas as mulheres responderam questionário padronizado, com questões contemplando dados demográficos e comportamentais, nem todas as perguntas foram respondidas por todas as mulheres. Dados clínicos e laboratoriais foram incluídos no estudo.

Os exames laboratoriais assim como os testes sorológicos foram realizados no Laboratório do Hospital Couto Maia, Laboratório Central ( LACEN) e outros da rede pública estadual. Para 0 teste HIV, foi utilizado o teste Ortho Diagnostics EIA como triagem e imunofluorescencia indireta (IFI) ou Western Blot como confirmatório; a carga viral foi realizada pela técnica de Protein Chain Reation (PCR) (Biomerieux) e a contagem de células $\mathrm{TCD}^{+} / \mathrm{CD} 8^{+}$por citometria de fluxo (FacsCalibur - BD) .

A análise estatística foi descritiva e realizada com auxilio do programa SPSS versão 11 para Windows.

\section{RESULTAD0S}

Foram estudadas 82 mulheres com idade média de $32 \pm 7,2$ anos; $63 / 81$ (77,8\%) tinham nível de escolaridade entre analfabetismo e primeiro grau incompleto. A renda mensal foi inferior a um salário mínimo em 31/77 (44,3\%) e inferior a três salários mínimos em 65/77 (84,3\%). 0 desemprego ou trabalho esporádico foi relatado por $63 / 76(82,5 \%)$ das entrevistadas. Quanto aos hábitos de vida, 35/76 (46\%) referiam ser ou terem sido fumantes, 30/75 (40\%) referiam uso de bebidas alcoólicas e 7/77 (9\%) utilizavam drogas injetáveis.

Nos antecedentes médicos, 44/63 (69,8\%) referiam consulta com ginecologista, 9/70 (13\%) não tinham tido nenhuma gestação e 15/82 (18,3\%) estiveram grávidas durante o período de acompanhamento. 0 abortamento foi relatado por 35/65 (54\%) das mulheres e destas, 19 (29,2\%) admitiam 0 abortamento provocado. A transfusão sanguínea foi relatada por 14/75 (18,6\%). 0 uso de algum método contraceptivo foi relatado por 39/65 (65\%), sendo que a laqueadura tubária e 0 uso de pílulas foram os mais freqüentes. 0 uso de preservativos foi relatado por $9 / 65(13,9 \%)$ das mulheres. 0 número de parceiros sexuais na vida variou de um a numerosos e 42/61 (70\%) destas mulheres tiveram entre um e cinco. Os dados demográicos, comportamentais e de antecedentes médicos e obstétricos podem ser vistos na Tabela 1.

Os exames referentes ao diagnóstico constantes nos prontuários foram testes imunoenzimáticos (ELISA) em 67/ 82( $82 \%$ ) dos casos, Western Blot ou imunofluorescência indireta em 53/82 (65\%) dos casos. Os exames para acompanhamento da infecção pelo HIV, especificamente a quantificação de carga viral e as subpopulações de linfócitos T CD4+ e CD8+, foram realizados por 56/82 (68,3\%). 0 número de cópias virais variou de inferior ao limite de detecção a 11 milhões e 0 T CD4+ de um a 1038 na primeira medida, sendo que 25/56 (44,6\%) tinham T CD4+ inferior a 200 cels $/ \mathrm{mm}^{3}$.

Outros exames sorológicos que foram realizados para 0 acompanhamento destas mulheres e os resultados podem ser vistos na Tabela 2. 
Tabela 1 - Dados demográficos, comportamentais e antecedentes médicos de 82 mulheres com HIV/AIDS.

\begin{tabular}{|c|c|}
\hline Dados demográficos & № / № de pacientes que responderam (\%) \\
\hline Idade (média \pm Desvio Padrão) $32 \pm 7,2$ & \\
\hline Grau de instrução & \\
\hline analfabeto/1ํㅡ grau & $63 / 81(77,8)$ \\
\hline $2^{0} \mathrm{Grau} /$ superior & $18 / 81(22,2)$ \\
\hline Trabalho & \\
\hline empregada & $13 / 76(17,1)$ \\
\hline desempregada/trabalho esporádico & $63 / 76(82,5 \%)$ \\
\hline Renda mensal & \\
\hline < 1 salário mínimo & $31 / 70(44,3)$ \\
\hline 1 - 5 salários mínimos & $35 / 70(50)$ \\
\hline > 5 salários mínimos & $4 / 70(5,7)$ \\
\hline Filhos & \\
\hline sim & $66 / 80(82,5)$ \\
\hline não & $14 / 80(17,5)$ \\
\hline Dados comportamentais & \\
\hline Número de parceiros na vida & \\
\hline$\leq 5$ & $42 / 61(68,9)$ \\
\hline $6-20$ & $11 / 61(18)$ \\
\hline$>20$ & $8 / 61(13,1)$ \\
\hline Etilismo & \\
\hline sim & $30 / 75(40)$ \\
\hline não & $45 / 75(60)$ \\
\hline Tabagismo & \\
\hline sim/ex-fumante & $35 / 76(46)$ \\
\hline não & $45 / 76(54)$ \\
\hline Uso de drogas injetáveis & \\
\hline sim & $7 / 77(9,1)$ \\
\hline não & $70 / 77(90,9)$ \\
\hline Antecedentes médicos & \\
\hline história de transfusão sanguinea & \\
\hline sim & $14 / 75(18,6)$ \\
\hline não & $61 / 75(81,4)$ \\
\hline Acompanhamento ginecológico & \\
\hline sim & $44 / 63(69,8)$ \\
\hline não & $19 / 63(30,2)$ \\
\hline Métodos contraceptivos & \\
\hline preservativo ( sozinho ou associado) & $9 / 65(13,9)$ \\
\hline laqueadura & $11 / 65(16,9)$ \\
\hline pílula/DIU/outros & $19 / 65(29,2)$ \\
\hline não usa & $26 / 65(40)$ \\
\hline Abortamento & \\
\hline espontâneo & $16 / 65(24,6)$ \\
\hline provocado & $19 / 65(29,2)$ \\
\hline não & $30 / 65(46,2)$ \\
\hline Gravidez após o diagnóstico & \\
\hline sim & $15 / 82(18,3)$ \\
\hline não & $67 / 82(81,7)$ \\
\hline
\end{tabular}

Tabela 2 - Soroprevalência para sífilis, hepatite B, hepatiteC, toxoplasmose e citomegalovirose em 82 mulheres com HIV/AIDS.

\begin{tabular}{lcc}
\hline Exame sorológico & $\begin{array}{c}\text { N pacientes que realizaram } \\
\text { exames/população }(\%)\end{array}$ & $\begin{array}{c}\mathrm{N}^{\mathrm{p}} \text { pacientes com } \\
\text { testes positivos }(\%)\end{array}$ \\
\hline Síflis - VDRL & $39 / 82(47,6)$ & $5 / 39(12,8)$ \\
Hepatite B - AgHbs & $34 / 82(41,5)$ & $0 / 34(0)$ \\
Hepatite C & $22 / 82(26,8)$ & $7 / 22(31,8)$ \\
Toxoplasmose & $28 / 82(34,1)$ & $17 / 28(77,3)$ \\
Citomegalovírus & $22 / 82(26,8)$ & $20 / 22(90,9)$ \\
\hline
\end{tabular}

Infecções oportunistas foram observadas ao longo do acompanhamento, das quais destacamos as mais freqüentes: monilíase oral (31/82 - 37,8\%); toxoplasmose cerebral (10/82 - 12,2\%); monilíase esofágica ( 6/82 - 7,3\%); herpes zóster (5/ $82-6,1 \%$ ) e a pneumonia possivelmente por Pneumocystis carinii $(3 / 82-3,7 \%)$.

Das mulheres estudadas 48 (58,5\%) eram portadoras do HIV 34 (41,5\%) tinham AIDS, diagnóstico baseado na contagem de T CD4+ inferior a $200 \mathrm{cel} / \mathrm{mm}^{3}$ e/ou por apresentarem uma ou mais das seguintes doenças definidoras: monilíase esofágica, toxoplasmose cerebral, pneumonia por Pneumocystis carinii, diarréia por Cryptosporidium e esofagite por Cytomegalovirus.

0 acompanhamento clínico ocorreu regularmente em 61 $(74,4 \%)$ casos, oito $(9,8 \%)$ mulheres evoluíram para óbito e $13(15,8 \%)$ mulheres descontinuaram 0 acompanhamento.

0 tratamento anti-retroviral, assim como as profilaxias, foram instituídas baseados nos documentos editados anualmente pelo Ministério da Saúde.

\section{DISCUSSÃ0}

Este artigo visa trazer para a discussão 0 acompanhamento de pacientes do sexo feminino com HI/AIDS que ocorre rotineiramente nos SAE, refletindo, portanto as condições da assistência real.

Quinze mulheres chegaram ao serviço sem 0 resultado do exame sorológico, apenas referindo ser 0 exame positivo. A destruição do resultado do exame pela própria paciente, tanto por negação da doença, como por medo do conhecimento deste por pessoas do seu convívio familiar e 0 extravio devido ao tempo decorrido entre o resultado e a procura do atendimento, foram os fatores levantados para explicação desta ocorrência. Todas as mulheres que chegaram sem 0 resultado do exame diagnóstico foram acompanhadas e tiveram o diagnóstico da infecção pelo HIV, seja pela realização da carga viral e linfócitos T CD4+, ou por presença de doenças oportunistas relacionadas a AIDS.

As mulheres estudadas apresentam indicadores sociais baixos e a escolaridade desta amostra (77,8\% de analfabetas e primeiro grau) é inferior a das mulheres brasileiras cujos casos foram notificados ao Ministério da Saúde (60,4\%), sendo que esta diferença pode ser creditada a origem destas mulheres, principalmente da região sudeste do Brasil, onde os indicadores sociais são melhores ${ }^{19}$. A renda mensal inferior a um salário mínimo em $45 \%$ dos casos, pode ser comparada a renda média das mulheres nordestinas, que segundo o IBGEé de $\mathrm{R} \$ 164,20^{14}$. Quanto ao trabalho, percebemos que $82,9 \%$ não tinham emprego. Este número é muito expressivo, mesmo quando comparamos aos índices de desemprego da região metropolitana de Salvador, que é 0 maior do país e chega a $32 \% 14$. Como a população estudada é composta apenas por mulheres, e todos os índices utilizados para medida de pobreza estão em pior situação que os da população em geral, esses fatos corroboram a afirmação de alguns autores, que atribuem às mulheres 0 maior contingente de pobres ${ }^{1025}$. 
Os aspectos comportamentais mostram que as características destas mulheres não são compatíveis com os grupos de risco ou mesmo comportamentos de risco, utilizados no início da epidemia e, felizmente, já superados na abordagem do Ministério da Saúde, especialmente nas campanhas de prevenção. Nesta amostra, menos de $15 \%$ das mulheres referiam 20 ou mais parceiros na vida e um quarto da amostra é composta por mulheres com um único parceiro sexual na vida. Ainda entre os aspectos comportamentais, chama a atenção o pequeno percentual de uso de preservativos (13,9\%), revelando não somente desinformação, compatível com o nível de escolaridade, mas principalmente 0 não domínio das mulheres dos meios de proteção, isto porque as mulheres entendem que a não utilização de preservativos pode significar confiança no parceiro, crença na relação monogâmica e compromisso com a relação ${ }^{27}$. Estas características das mulheres deste grupo as enquadram na denominação utilizada pela pesquisadora Dirce Guilhem, de escravas do risco, por serem, na sua maioria, mulheres com parceiros fixos e que adquiriram a AIDS desses parceiros ${ }^{410}$.

Quanto a outros comportamentos que poderiam ser responsáveis pela aquisição do HIV, destacamos a baixa referência ao uso de drogas injetáveis $(8,5 \%)$ quando comparamos com os dados nacionais $(13,6 \%)$; a transfusão sanguínea relatada por $17 \%$ das mulheres estudadas é muito superior aos dados nacionais $(1,7 \%)$, entretanto, a consideração da transfusão como forma de transmissão fica prejudicada por não ter havido avaliações complementares deste dado. Na Bahia, a categoria exposição sanguínea ( sem diferenciação do uso de drogas injetáveis e transfusão sanguínea) é responsável por 16,6\% dos casos em mulheres ${ }^{20}$.

No período do estudo, 21 mulheres descontinuaram 0 acompanhamento. Destas, oito evoluíram para o óbito e em 13 0 motivo foi desconhecido. Das mulheres que morreram, pelo menos duas, não morreram por complicações clínicas, sendo que a primeira cometeu suicídio e a segunda faleceu em conseqüência do parto. Aavaliação destas oito mulheres mostra que apenas duas delas realizaram os exames necessários ao acompanhamento, com número de linfócitos T CD4+ baixos (110 e 83), assim como a carga viral elevada (340.000 e 1.300.000). A deficiência imunológica destas pacientes pode indicar que sequer tiveram tempo para realização das avaliações laboratoriais necessárias. Das treze pacientes que não retornaram ao ambulatório, quatro realizaram os exames de T CD4+ (que foram maiores que 200 cels $/ \mathrm{mm}^{3}$ ) e carga viral ( três inferiores a 21.000 cópias) e ao contrário das que evoluíram para o óbito, apresentavam os indicadores virológicos e imunológicos mais satisfatórios. A descontinuidade pode ter ocorrido devido a estabilidade clínica, não se podendo descartar a ocorrência de óbito, assim como a transferência do acompanhamento para outro serviço.

0 acesso aos exames essenciais para 0 acompanhamento virológico e imunológicos foi efetivo na grande maioria (70\%) das pacientes. As maiores dificuldades para realização destes exames ocorreram em pacientes provenientes do interior do estado, onde os exames não são disponibilizados nas suas cidades de origem, e em Salvador existe centralização, inclusive a coleta, no Laboratório Central (LACEN), dificultando o acesso. Em contraposição a esta constatação, 0 acesso aos exames sorológicos foi pequeno, até mesmo para exames de baixo custo como 0 VDRL, realizado por menos da metade da população estudada. A universalização do acesso aos exames essenciais para 0 acompanhamento adequado dos pacientes com HIV deve ser perseguida, inclusive com a possibilidade de realização da coleta no local onde o paciente é atendido.

Quando a avaliação das soroprevalências, a da sífilis foi realizada apenas com 0 teste não treponêmico - VDRL, não confirmado com os testes treponêmicos devido a dificuldade de acesso a estas provas sorológicas na rede pública da Bahia. A prevalência de 12,8\% pode caracterizar especialmente a sífilis latente ou tardia. A Organização Mundial de Saúde estima que para a população de 15 a 45 anos, a prevalência seja de 0,5\%; em estudos sentinelas em gestantes observa-se a prevalência de $4 \%$ e em profissionais do sexo, esta taxa chega a $37 \%{ }^{20}$. A soroprevalência para os vírus da hepatite $\mathrm{B}(\mathrm{AgHbs})$ e hepatite $\mathrm{C}$ (sem teste confirmatório) foi de zero/34 e 7/22 (31,8\%), respectivamente. Dados semelhantes foram obtidos em doadores de sangue HIV positivos, em Londrina - PR, onde de 39 doadores positivos para HIV, 1(2,6\%) foi AgHbs positivos e 10 (25,6\%) foram anti-HCV positivos ${ }^{26}$. Das sete mulheres que tiveram 0 teste inicial positivo para hepatite $\mathrm{C}$, uma referia uso de droga injetável e outra tinha história de transfusão sanguínea. A soroprevalência para toxoplasmose $(77,3 \%)$ significa infecção latente pelo Toxoplasma gondii e é importante para decisão de profilaxia. É grande a variação da prevalência desta infecção ao redor do mundo e nos EUA é de 30\%7. A infecção latente pelo citomegalovírus foi detectada em $90 \%$ das mulheres estudadas e este dado é compatível com a literatura médica que mostra esta infecção presente na maioria dos adultos infectados pelo HIV?

Quanto às infecções oportunistas detectadas nesta população, a proporção é inferior aos números relatados para os casos notificados pelo Ministério da Saúde, entretanto a nossa população é composta tanto por mulheres com AIDS, como por portadoras do HIV ${ }^{11}$.

\section{AGRADECIMENTOS}

Adiretoria do Hospital Couto Maia e especialmente as equipes do ambulatório, da farmácia e a assistente social Alice Maria Carvalho, pelo apoio na organização deste trabalho.

\section{REFERÊNCIAS BIBLIOGRÁFICAS}

1. Anderson KH, Mitchell JM. Differential access in the receipt of antiretroviral drugs for the treatment of AIDS and its implications for survival. Archives of Internal Medicine 160: 3114-3120, 2000.

2. Baggaley RC, Needham D. Africa's emerging AIDS- orphans crisis. Canadian Medical Association Journal 156: 873-875, 1997.

3. Bobat R, Coovadia H, Coutsoudis A, Moodley D. Determinants Of MotherTo-Child Transmission Of Immunodeficiency Virus Type 1 Infection In A Cohort From Durban, South African. Pediatrics Infectious Diseases Journal 15: 604-610, 1996. 
4. Chatterjee N. They have not heard of AIDS: HIV/AIDS awareness among married women in Bombay. Public Health 113: 137-140, 1999.

5. Collen K, Lobb D. The British Columbia positive women's survey: a detailed profile of 110 HIV - infected women. Canadian Medical Association Journal 158: 317-323, 1998

6. Farzadegan H, Hoover DR, Astemborski J, Lyles CM, Margolick JB, Markham RB, Ouinn TC, Vlahov D. The Lancet 352: 1510-1514, 1998.

7. Feinberg J, Maenza J. Primary medical care. In: Anderson J (ed) A guide to the clinical care of women with HIV, preliminary edition, US Government Printing Office, Washington DC, p. 79-138, 2000.

8. Gandhi M, Bacchetti P, Miotti P, Quinn TC, Veronese F, Greenblatt M. Does patient sex affect human immunodeficiency virus levels? Clinical of Infectious Diseases 35: 313-322, 2002.

9. Greenblat RM, Hessol AN. Epidemiology and natural history of HIV infection in women. In: Anderson J ( ed) A guide to the clinical care of women with HIV, preliminary edition, US Government Printing Office, Washington DC, p. 1-33, 2000.

10. Guilhem D. Escravas do Risco: Bioética, Mulheres e AIDS. Tese apresentada ao Programa de Pós-graduação em Ciências da Saúde, área de concentração bioética, Universidade de Brasília 2000.

11. Guimarães MDC. Estudo Temporal das doenças associadas a AIDS no Brasil, 1980 - 1999. Cadernos de Saúde Pública 16: 21-36, 2000.

12. Guinan ME, Leviton L. Prevention of HIV infection in women: overcoming barriers. Journal of the American Medical Women Association 50: 74-77, 1995.

13. Hankins C. Sexual transmission of HIV to women in industrialized countries. World-Health-Stat-Q 49: 106-114, 1996.

14. Instituto Brasileiro de Geografia e Estatística. Censo 2000. Extraído de http://ibge.gov.br/censo, acesso em 02/02/2003.

15. Laga N, Nzila N, Goeman J. The interrelationship of sexually transmitted diseases (STDs) as risk factors for HIV infection: implications for the control of both epidemics in Africa. AIDS 5: 55-66, 1991.

16. Levine A. HIV disease in women. Health Care Communications Group. Extraído de: http: // www. healthcg.com/hiv/women, acesso em 11/10/1997.

17. Mboi N. Women and AIDS in south and southeast Asia: the challenge and the response. World-Health-Stat-Q 49:94-105,1996.

18. Ministério da Saúde. Aids no Brasil: um esforço conjunto governosociedade. Coordenação Nacional de DST e Aids - Brasília, 1998.
19. Ministério da Saúde. Boletim Epidemiológico AIDS. Ano XII № 02- Semana Epidemiológica 09 a 21, 1999.

20. Ministério da Saúde. Boletim Epidemiológico AIDS. Ano XVI № 01- Semana Epidemiológica 14 a 52, 2003.

21. Ministério da Saúde. Dados de AIDS no Brasil ( Banco de dados). Disponível em: http://www.aids.gov.br/, acesso em 30 de junho de 2003a.

22. Ministério da Saúde. Dados de DST. Estudos publicados de 1987 a 1997. Disponivel em: http://www.aids.gov.br/, acesso em 30 de junho de 2003b.

23. Minkoff H, Dehovitz JÁ. HIV infection in women. AIDS Clinical Care 5: 3440, 1991

24. Minkoff H, Feldman J, DeHovitz J, Landesman S, Burk R. A longitudinal study of human papillomavirus carriage in human immunodeficiency virus-infected women. American Journal of Obstetrics and Gynecology 178: 982-986, 1998.

25. Parker R, Camargo Jr KR. Pobreza e HIV/AIDS: aspectos antropológicos e sociológicos. Cadernos de Saúde Pública 16: 89-102, 2000

26. Reiche EM, Vogler IH, Marimoto HK, Bortoliero AL, Matsuo T, Yuahasi KK, Cancian SJ, Koguichi RS. Evaluation of surrogate markers for human immunodeficiency virus infection among blood donors at the blood bank of "Hospital Universitário Regional Norte do Parana”, Londrina, PR, Brazil. Revista do Instituto de Medicina Tropical de São Paulo 45: 23-27, 2003.

27. Sherman SA, Latkin CA. Intimate relationship characteristics associated with condom use among drug users and their sex partners: a multilevel analysis. Drug and Alcohol Dependence 64: 97-104, 2001.

28. Silversides A. With HIV prevalence among women increasing, more provinces encourage prenatal testing. Canadian Medical Association Journal 158: 1518-1519, 1998.

29. Sterling TR, Vlahov D, Astemborski J, Hoover D, Margolick JB, Quinn TC. Initial plasma HIV-1 RNA levels and progression to AIDS in women and men. The New England Journal of Medicine 344: 720-725, 2001.

30. Szwarcwald CL, Andrade CLT, Castilho EA. Estimativa do número de órfãos decorrentes da AIDS materna, Brasil, 1987- 1999. Cadernos de Saúde Pública 16: 129-134, 2000

31. Tortu S, Beardsley M, Deren S, Williams M, McCoy HV, Stark M, Estrada A, Goldstein M. HIV infection and patterns of risk among women drug injectors and crack users in low and high sero-prevalence sites. Aids Care 12: $65-76,2000$.

32. World Health Organization. Joint United Program on HIV/AIDS ( UNAIDS) and World Health Organization (WHO). AIDS epidemic update December. Extraído de: http://www.unaids.org. 02/12/2002.

33. Wortley PM, Fleming PL. AIDS in women in the United States: recent trends. Journal of American Medical Association 278: 911-916, 1997. 